\title{
Systematic Birth Preparation Programs Positively Influence the Childbirth Fear: A cross-sectional study.
}

\author{
Sebnem Alanya Tosun ${ }^{1(\mathbb{I D})}$ Eda Sahin ${ }^{2(\mathrm{ID})}$ Enis Ozkaya ${ }^{3(\mathrm{ID})}$ Muhammet Bulut ${ }^{4(\mathrm{ID})}$ \\ Ismail Bugra Bilen ${ }^{5(\mathbb{D})}$ Mehmet Sipahi $^{1(\mathrm{ID})}$
}

\begin{abstract}
${ }^{1}$ Department of Obstetrics and Gynaecology, Faculty of Medicine, Giresun University, Giresun, Turkey, ${ }^{2}$ Department of Obstetrics and Gynaecology Nursery, Faculty of Health Sciences, Giresun University, Giresun, Turkey ${ }^{3}$ Department of Obstetrics and Gynaecology, Zeynep Kamil Woman and Children Education and Research Hospital, Health Sciences University, Istanbul, Turkey ${ }^{4}$ Department of Pediatrics, Faculty of Medicine, Giresun University, Giresun, Turkey. ${ }^{5}$ Giresun University Education and Research Hospital, Giresun, Turkey
\end{abstract}

Copyright@ Author(s) - Available online at https://dergipark.org.tr/en/pub/mbsjohs Content of this journal is licensed under a Creative Commons Attribution-NonCommercial 4.0 International License,

Received: 08 May 2021, Accepted: 09 August 2021, Published online: 31 August 2021 (C) Ordu University Institute of Health Sciences, Turkey, 2021

\begin{abstract}
Objective: The primary target of birth preparation program is guiding women to realistic expectations for the birth experience. The aim of the present study is to evaluate the influence of a systematic multidisciplinary birth preparation program on delivery expectation, childbirth fear, mode of delivery and neonatal outcomes. Methods: 159 nulliparous pregnant women in their 3rd trimester were enrolled in this cross-sectional cohort study between January 2018 and March 2020. Women who participated to the systematic birth preparation program were grouped as Group A $(n=80)$ and those who refused to participate were considered Group B $(\mathrm{n}=79)$. Fear of childbirth was scanned by Wijma Delivery Expectancy Questionnaire Version-A; sociodemographic and obstetric features were assessed through a self-developed survey by face-to-face interview. The mode of delivery, labor induction needs, cesarean indications, birth weights, APGAR scores, newborns hospitalization requirements if any were noted.

Results: The Wijma-A mean score was $44.60 \pm 19.63$ in those who attended the systematic birth preparation program and $72.05 \pm 24.82$ in those who did not $(\mathrm{p}<0.001)$. Childbirth fear was significantly lower in attended group when pregnant women were evaluated according to the four different level childbirth fear categories $(p<0.001)$. The birth weights were significantly higher in attended group $(p=0.017)$. There was no significant difference between the two groups in terms of mode of delivery, APGAR scores, neonatal hospitalization and labor induction requirements ( $p>0.05)$.

Conclusion: The present study shows that systematic and multidisciplinary birth preparation program may positively influence the childbirth fear and increase the birth weights of neonates.

Key words: Systematic birth preparation program, pregnancy, vaginal delivery, childbirth fear, Wijma-A delivery expectancy questionnaire.
\end{abstract}

Suggested Citation: Alanya Tosun S. Sahin E, Ozkaya E, Bulut M, Bilen IB, Sipahi M. Systematic Birth Preparation Programs Positively Influence the Childbirth Fear: A cross-sectional study...Mid Blac Sea Journal of Health Sci, 2021; 7(2):254-261

Address for correspondence/reprints:

Şebnem Alanya Tosun

Telephone number: + 90 (532) 5758395
E-mail: sebnem_alanya@hotmail.com

Note: This study was presented in TJOD (Turkish Society of Gynaecology and Obstetrics) Online Symposium on 4th December 2020. (Oral presentation) 


\section{Introduction}

Pregnancy is the extra-ordinary important and excited period in reproductive aged women's life. In this period, the psychological as well as physical well-being is necessary to minimize perinatal morbidity and mortality. Uncomplicated delivery with proper antenatal follow-up is the main goal. Although vaginal route of delivery is a natural process, most of the women have fear of childbirth during pregnancy (1). Childbirth fear increases the delivery durations, women's request for cesarean sections, leads to use more labor induction agents and accordingly increasing the elective or urgent cesarean sections rates and perinatal morbidity (2). Furthermore, increasing rates of perinatal morbidity may lead mothers to postpartum depression and lack of lactation (3).

The causes of childbirth fear are classified as biological situations, psychological situations and lack of social support (1). Some studies indicates that nulliparous women have higher levels of childbirth fear than multiparous women (4). Some studies show that educational level positively influences the childbirth fear, but there are also some studies which did not state any relationship $(5,6)$.

Systematic and multidisciplinary birth preparation programs are offered to ensure that the pregnancy process continues physically and psychologically healthy, to guide women to realistic expectations for the birth experience, to prevent unsatisfactory situations as postpartum depression, sexual dysfunction, to increase the success of postpartum breastfeeding, and maintaining a healthy birth experience and puerperium (7). Pregnant women can practice the necessary physical activities to prevent lumbopelvic pain and facilitate delivery process (8). Techniques for pain reduction and tips for women's autonomy are taught for to minimize the maternal request for a cesarean section. Adequate knowledge about the second stage of the labor may help to reduce fear; pain relief techniques and breath exercises may encourage a fearless vaginal route delivery (9).

This study was design to evaluate the effectiveness of systematic birth preparation program on delivery expectancy and childbirth fear. Secondly, we investigated the relation of systematic birth preparation program with the mode of delivery and neonatal outcomes.

\section{Methods}

\section{Systematic Birth Preparation Program}

Giresun University Maternal and Children Disease's Education and Training Hospital is a tertiary center and is the first center in black sea part of Turkey that is qualified as "Mother-friendly Hospital" by the Ministry of Health. It has been providing a systematic birth preparation program to 2nd and 3rd trimester pregnant women named "Pregnant School" since January 2017. Between 18 and 22 gestational weeks, pregnant women are informed about the program in the outpatient clinics and those who wish to participate are enrolled. Each education group consists of 8 participants and 4 education session once in a week for 1 month. The contents of the sessions, each of which lasted 3 hours, are given in Table 1. The signs and stages of labor, breathing exercises, pain relief techniques are given to reduce the childbirth fear and to encourage the vaginal delivery. Hydrotherapy, reflexology, yoga and pilates are examples of pain relief techniques which are taught to the participants to control birth pain. Educations are carried out with Power Point presentations and flip-chart. Childbirth models, exercise balls, gymnastic mats and lactation pumps are present to apply. An obstetrician and gynecologist, a nutritionist, a psychologist, a lactation consultant, and a nurse constitute the educational staff. The partners are also attending to the 4 th session of the program and a certificate is given to the women at the end. Meanwhile, both groups are following routine antenatal care with physicians.

\section{Participants}

This is a cross-sectional cohort study of 159 healthy nulliparous pregnant women admitted to Giresun University Maternal and Children Disease's Education and Training Hospital for antenatal follow up between January 2018 and March 2020. Initially 171 healthy nulliparous women were included; 12 patients (5 patients from Group A and 7 patients from group B) did not give birth in the same hospital and excluded from the study. The study was approved by the Giresun University, Ethical Committee for Human Research (Institutional Review Board: 09.11.2020/09). 
Table 1. The systematic birth preparation program sessions.

\begin{tabular}{|c|c|c|c|c|c|c|c|}
\hline Session 1 & & Session & & Session 3 & & Session 4 & \\
\hline Lecture & Trainer & Lecture & Trainer & Lecture & Trainer & Lecture & Trainer \\
\hline $\begin{array}{l}\text { The } \\
\text { anatomy } \\
\text { and } \\
\text { function } \\
\text { of the } \\
\text { reproducti } \\
\text { ve organs }\end{array}$ & $\begin{array}{l}\text { Obstetricia } \\
\text { n \& } \\
\text { Gynecolog } \\
\text { ist }\end{array}$ & $\begin{array}{l}\text { Antenat } \\
\text { al } \\
\text { exercise } \\
\text { s and } \\
\text { yoga }\end{array}$ & Nurse & $\begin{array}{l}\text { The } \\
\text { signs } \\
\text { and } \\
\text { stages of } \\
\text { labor }\end{array}$ & $\begin{array}{l}\text { Obstetricia } \\
\text { n \& } \\
\text { Gynecolog } \\
\text { ist }\end{array}$ & $\begin{array}{l}\text { Postpartum } \\
\text { contracepti } \\
\text { on } \\
\text { methods }\end{array}$ & $\begin{array}{l}\text { Obstetricia } \\
\text { n \& } \\
\text { Gynecolog } \\
\text { ist }\end{array}$ \\
\hline $\begin{array}{l}\text { The } \\
\text { growth of } \\
\text { fetus }\end{array}$ & $\begin{array}{l}\text { Obstetricia } \\
\text { n \& } \\
\text { Gynecolog } \\
\text { ist }\end{array}$ & $\begin{array}{l}\text { Perineal } \\
\text { massage } \\
\text { for } \\
\text { vaginal } \\
\text { route } \\
\text { delivery }\end{array}$ & Nurse & $\begin{array}{l}\text { Breath } \\
\text { exercise } \\
\mathrm{S}\end{array}$ & Nurse & $\begin{array}{l}\text { Antenatal } \\
\text { and } \\
\text { postpartum } \\
\text { sexual life }\end{array}$ & Nurse \\
\hline $\begin{array}{l}\text { General } \\
\text { knowledg } \\
\text { e about } \\
\text { antenatal } \\
\text { period }\end{array}$ & $\begin{array}{l}\text { Obstetricia } \\
\text { n \& } \\
\text { Gynecolog } \\
\text { ist }\end{array}$ & $\begin{array}{l}\text { Diet } \\
\text { during } \\
\text { pregnan } \\
\text { cy }\end{array}$ & $\begin{array}{l}\text { Nutrition } \\
\text { ist }\end{array}$ & $\begin{array}{l}\text { Pain } \\
\text { relief } \\
\text { techniqu } \\
\text { es }\end{array}$ & $\begin{array}{l}\text { Psycholog } \\
\text { ist }\end{array}$ & $\begin{array}{l}\text { Breastfeedi } \\
\text { ng and } \\
\text { neonatal } \\
\text { care }\end{array}$ & $\begin{array}{l}\text { Lactation } \\
\text { consultant }\end{array}$ \\
\hline
\end{tabular}

Low-risk nulliparous pregnant women with healthy singleton pregnancies in their third trimester (between 28-40th gestational weeks), between the ages of 18-40, without psychiatric disorder and admitted to the antenatal care from the first trimester of their pregnancy were included to the study. Exclusion criteria were high-risk pregnancies like preeclampsia, multiple pregnancies or fetus with congenital anomalies, previous birth experience, adolescent pregnancies, maternal psychiatric disorders, substance abuse, single mothers, planned Ceserean births, history of sexual transmitted disease and participation to different birth preparation programs such as hypnobirthing or mindfulness. Also, women who quited the program before completing were excluded from the study.

Group A is study group which consists of 80 nulliparous patients who fully completed the systematic birth preparation program and Group B is control group which includes 79 nulliparous patients who never attend to the program. They were asked to complete the self-developed survey and the validated Wijma A Birth Expectancy Questionnaire- version A (W-DEQ-A) in their 3rd trimester (28-40 weeks of gestation).
Self-developed survey and Wijma Birth Expectancy Questionnaire Version-A (W-DEQ-A)

Baseline socio-demographic and obstetric features included maternal age (yrs), gestational age at the time of survey, educational level, maternal systemic diseases such as presence of diabetes, obesity or cardiac problems prior to pregnancy, paternal emotional support, whether there is a planned pregnancy and if they had different education options other than systematic birth preparation program were filled through a short self-developed survey with face-to face interview. Gestational age was calculated according to the last menstrual period, or the first trimester crown-rump length of the fetus was used for the ones which do not correlate with the last menstrual period date.

The participants were asked to fill the validated W-DEQ-A (10). It was prepared for screening feelings and thoughts of pregnant women about their labor, and it is useful to outline how they imagine their labor will be. There are 33 items in this Likerttype scale, whose translation has reliability and validity studies and measures pre-natal anxiety and fear (11). Each statement is scored between 0 and 5, totally has six degrees. The scale's minimum score is 0 and the maximum score is 165. As the score increases, anxiety and childbirth fear is rising. During the analysis of the data, the scores were grouped into four categories, a score $<37$ shows low level of fear, a score between 38-65 shows moderate level of fear, 
a score between 66-84 shows severe level of fear and a score above 85 shows very severe level of fear.

After the completion of the pregnancy, type of the delivery, if there is requirement for labor induction, cesarean indication if any, birth weight, neonatal APGAR scores, neonatal hospitalization or intensive care need and its indication were noted. The fetal distress indication was based on Dellinger et al. (12), prolonged labor was defined according to Cohen et al. (13) and the cephalopelvic disproportion criteria was evaluated according to Maharaj (14). All vaginal deliveries were carried out in two different rooms under equal conditions by midwives who received the same in-service training in the last year. Epidural analgesia was not applied, and episiotomy was routinely performed in primiparous patients.

The primary outcomes were the comparison of $\mathrm{W}$ DEQ-A mean scores between group A and group B. Secondary outcomes were the relation of the birth education program with the mode of delivery and the neonatal outcomes.

\section{Statistical Analysis}

Statistical analyses were performed by using SPSS Statistics version 24.0 (IBM Corporation, Armonk, New York, USA). Number (n), frequency (\%) for discrete data and mean \pm standard deviation $(\mathrm{X} \pm \mathrm{SD})$ for continuous data were used. Kolmogorov Smirnov Test, histogram, skewness and kurtosis values were used to evaluate whether the data conformed to the normal distribution. As the data showed normal distribution, Chi-square Test and Independent Sample t Test was used among parametric tests. The $p$ value $<0.05$ was considered statistically significant.

\section{Results}

A total of 159 nulliparous pregnant women without a history of psychiatric illness were included. 80 pregnant women who completed the program (Group A) and 79 pregnant women who never attended to the program (Group B) participated to the study. In the demographic analysis, the mean maternal age, week of gestation in which the questionnaire applied, maternal education level, presence of co-morbid systemic maternal disease, emotional support from the male partner were statistically similar in both groups (Table 2).

It was stated that $57 \%$ of 79 nulliparous pregnant women in group B who did not participate to the birth preparation program did not receive any alternative education, whereas $22.8 \%$ received information from the internet, $11.4 \%$ were informed by a healthcare professional and $8.9 \%$ applied to pregnancy education books (Table 2).
Wijma Birth Expectancy Questionnaire- Version A mean score was $44.60 \pm 19.63$ in group $A$ and 72.05 \pm 24.82 in group $\mathrm{B}$, it was determined that the anxiety of birth expectancy was significantly lower in patients who participated in the systematic and multidisciplinary birth preparation program $(\mathrm{p}$ $<0.001$ ) (Table 3). Distribution of pregnant women according to childbirth fear categories were statistically significantly different when two groups compared $(\mathrm{p}=0.000)$ (Table 3$)$.

When the mode of delivery was compared as spontaneous vaginal delivery or cesarean section, there was no statistically significant difference between the groups $(\mathrm{p}=0.805)$. When the birth weight of newborns was compared, it was found that the average was $3432.69 \pm 421.16$ in Group A and $3276.46 \pm 392.09$ in Group B which was statistically significant $(\mathrm{p}=0.017)$. There were no significant difference between the two groups in terms of APGAR scores, neonatal hospitalization and labor induction requirements ( $>0.05$ ) (Table 4).

\section{Discussion}

In the present study, the findings showed a significantly lower childbirth fear and higher birth weight in the systematic birth preparation attended group. However, the other factors such as the mode of delivery, APGAR scores, neonatal hospitalization and labor induction requirements did not change with attending the systematic birth preparation class.

Akca et al. reported that the systematic birth preparation program promotes better communication between patients and healthcare professional and increases postpartum women's satisfaction with the childbirth (7). Their study differs from our study as it was performed after the birth to analyze the birth experience. Furthermore, there are some studies that present mindfulness as an alternative program for the antepartum and postpartum period (15). SacristanMartin et al. applied the Mindfulness-based Childbirth and Parenting Program and they evaluated the progress of women in four different time zones as before program, after program, at three months and six months after childbirth mainly for perinatal depression (15). They found that an effective childbirth education program may be helpful to prevent perinatal depression. The present study evaluated the childbirth fear with the validated scale developed by a psychologist $(10,11)$. Our results showed that an easy to implement and low cost program is effective to decrease the childbirth fear and maternal anxiety. 
Table 2. Socio-demographic features of pregnant women

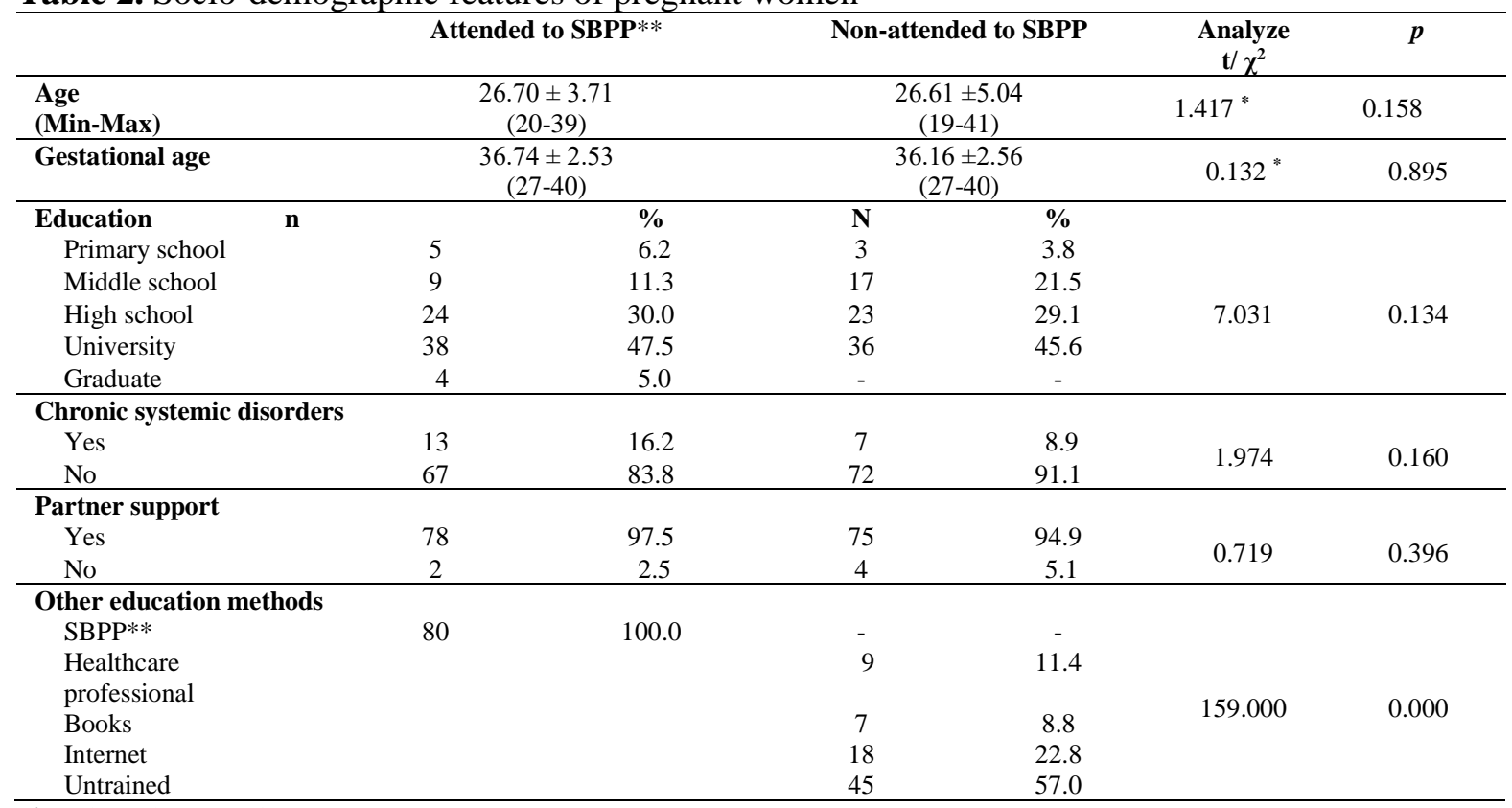

*: Independent Sample t Test

**: Systematic Birth Preparation Program

Table 3. Distribution of Pregnant Women According to mean value of the Wijma Birth Expectancy Questionnaire- Version A Total Score and Fear of Childbirth Categories

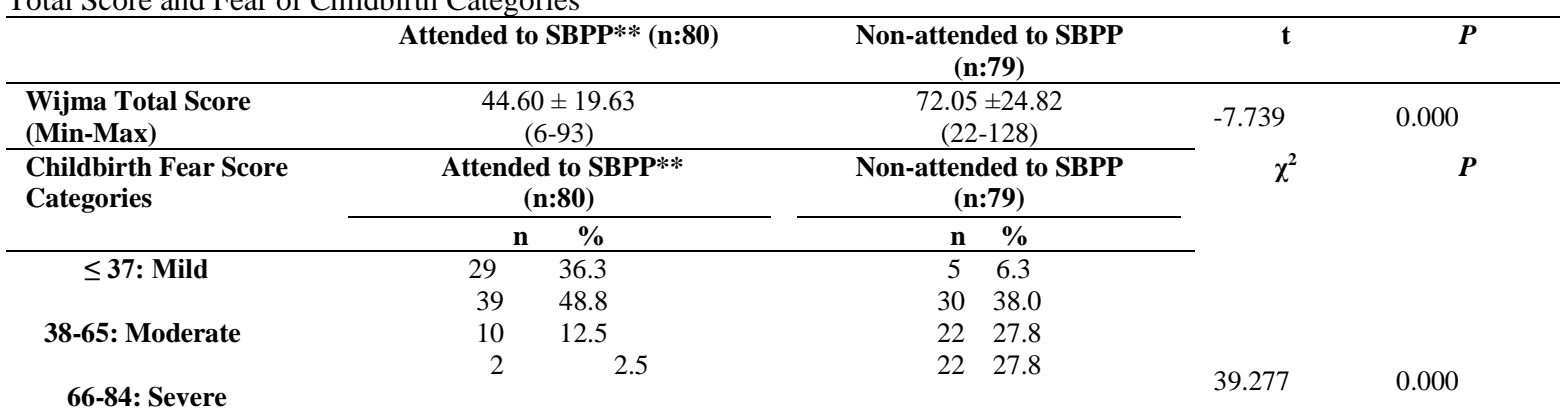

$\geq 85$ : Very severe

**: Systematic Birth Preparation Program 
Table 4. The relation of systematic birth preparation program with the mode of delivery and neonatal outcomes

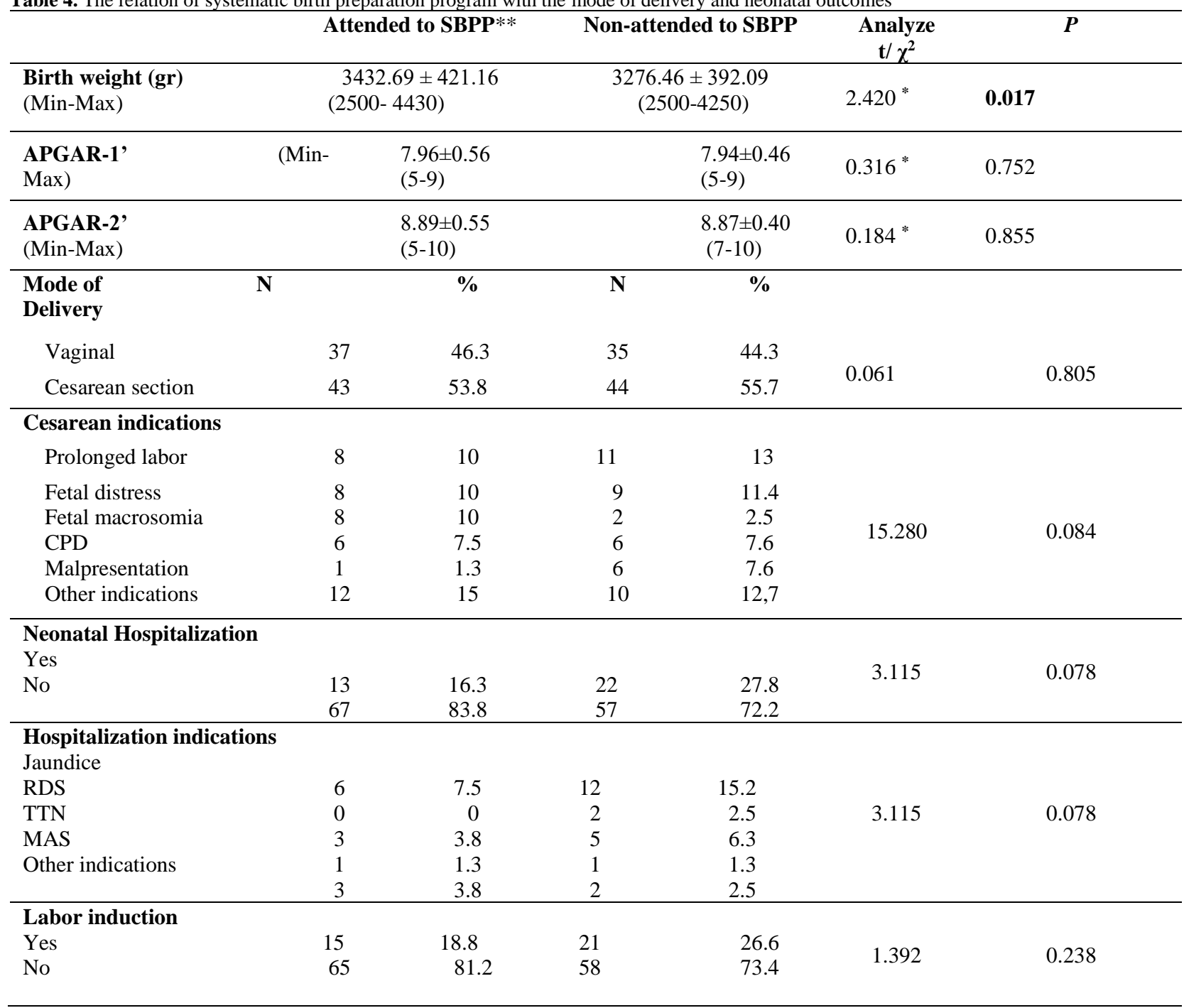

*: Independent Sample t Test

**: Systematic Birth Preparation Program

CPD: Cephalopelvic disproportion, APGAR: Activity, Pulse, Grimace, Appearance, Respiration, RDS: Respiratuar distress syndrome, TTN: Transient tachypnea of the newborn, MAS: Meconium aspiration syndrome.

The pregnancy period is influenced by childbirth fear and not thinking to tolerate labor pain is the important factor why women desire elective cesarean section and results with an increase in perinatal morbidity and mortality (16). Although cesarean section can be absolutely necessary to save the mother's and newborn's life in emergent conditions, this type of delivery is associated with increased perinatal and neonatal morbidity and mortality (17, 18). In order to minimize maternal request for cesarean section, Ozdemir et al. studied the effect of birth preparation program to vaginal delivery fear and quality of life (9). They found that vaginal deliveries were higher in women who requested the elective cesarean section before the program and participated in the program afterwards. However, the significant difference between two groups in vaginal and cesarean deliveries could not be confirmed in the current study.

In a randomized controlled trial with 1410 participants, midwife's psycho-education intervention positively influenced childbirth fear and improved vaginal birth rates (19). However, their sample included women who had previously experienced birth, carrying multiple gestations and having psychiatric health disorders. The strengths of our study are to compare the childbirth fear in nulliparous women who do not have any previous experience and to exclude the criteria such as psychiatric disorders, preterm delivery or multiple 
pregnancies. In literature, there are some studies about the correlation between childbirth fear and sociodemographic features as age, gestational week, parity, education level (20). In this study, the demographic features are not significantly different between study and control groups which make the results more realistic. Ketema et al. performed a meta-analysis about the relationship of mother's relevant education and obstetric complications and showed the usefulness of the program in daily practice (21).

The limited aspect is that the social and cultural factors that play an important role in the antenatal period should be considered in more detail in future studies. This study was carried on in a single center, but due to the different perspectives in different regions, women's view about vaginal delivery and childbirth fear may differ. Multicenter studies may be helpful to compare the effectiveness of systematic birth preparation class in different regions. Small number of participants is another limitation. Furthermore, the partner's social support can be evaluated in detail.

\section{Conclusion}

The systematic and multidisciplinary birth pre paration programs maintain realistic prenatal expectations for delivery and childbirth and seem to eliminate the birth anxiety.

Ethics Committee Approval: Giresun University Local Ethical Committee no: 09.11.2020/09

Peer-review: Externally peer-reviewed.

Author Contributions:

Concept: S.A.T, E.S; Design: S.A.T, E.S; Literature Search: E.O; Data Collection and Processing: S.A.T, M.B, M.S, Analysis or Interpretation: S.A.T, M.B, I.B.B, Writing: S.A.T, M.B, I.B.B,

Conflict of Interest: The authors declared no conflicts of interest with respect to the authorship and/or publication of this article.

Financial Disclosure: The authors received no financial support for the research and/or authorship of this article.

\section{References}

1. Koc AE, Colak S, Colak GV, Pusuroglu M, Hocaoglu C. Investigating fear of childbirth in pregnant women and its relationship between anxiety sensitivity and somatosensory amplification. Journal of obstetrics and gynaecology: the journal of the Institute of Obstetrics and Gynaecology. 2020 Apr 21:1-7.
2. Sercekus P, Vardar O, Ozkan S. Fear of childbirth among pregnant women and their partners in Turkey. Sexual \& reproductive healthcare: official journal of the Swedish Association of Midwives. 2020;24:100501. PubMed PMID: 32066117.

3. Silverman ME, Reichenberg A, Savitz DA, Cnattingius S, Lichtenstein P, Hultman CM, et al. The risk factors for postpartum depression: A population-based study. Depression and anxiety. 2017 Feb;34(2):178-87. PubMed PMID: 28098957. Pubmed Central PMCID: 5462547.

4. Soltani F, Eskandari Z, Khodakarami B, Parsa P, Roshanaei G. Factors contributing to fear of childbirth among pregnant women in Hamadan (Iran) in 2016. Electronic physician. 2017 Jul;9(7):4725-31. PubMed PMID: 28894527. Pubmed Central PMCID: 5586985.

5. Sydsjo G, Sydsjo A, Gunnervik C, Bladh M, Josefsson A. Obstetric outcome for women who received individualized treatment for fear of childbirth during pregnancy. Acta obstetricia et gynecologica Scandinavica. 2012 Jan;91(1):44-9. PubMed PMID: 21787365.

6. Haines H, Pallant JF, Karlstrom A, Hildingsson I. Cross-cultural comparison of levels of childbirthrelated fear in an Australian and Swedish sample. Midwifery. 2011 Aug;27(4):560-7. PubMed PMID: 20598787.

7. Akca A, Corbacioglu Esmer A, Ozyurek ES, Aydin A, Korkmaz N, Gorgen H, et al. The influence of the systematic birth preparation program on childbirth satisfaction. Archives of gynecology and obstetrics. 2017 May;295(5):1127-33. PubMed PMID: 28303340.

8. Miquelutti MA, Cecatti JG, Makuch MY. Developing strategies to be added to the protocol for antenatal care: an exercise and birth preparation program. Clinics. 2015 Apr;70(4):231-6. PubMed PMID: 26017787. Pubmed Central PMCID: 4418303.

9. Ozdemir ME, Cilingir IU, Ilhan G, Yildiz E, Ohanoglu K. The effect of the systematic birth preparation program on fear of vaginal delivery and quality of life. Archives of gynecology and obstetrics. 2018 Sep;298(3):561-5. PubMed PMID: 29961135.

10.Wijma K, Wijma B, Zar M. Psychometric aspects of the W-DEQ; a new questionnaire for the measurement of fear of childbirth. Journal of psychosomatic obstetrics and gynaecology. 1998 Jun;19(2):84-97. PubMed PMID: 9638601. 
11.Korukcu O, Kukulu K, Firat MZ. The reliability and validity of the Turkish version of the Wijma Delivery Expectancy/Experience Questionnaire (W-DEQ) with pregnant women. Journal of psychiatric and mental health nursing. 2012 Apr;19(3):193-202. PubMed PMID: 22260727.

12.Dellinger EH, Boehm FH. Emergency management of fetal stress and distress in the obstetric patient. Obstetrics and gynecology clinics of North America. 1995 Jun;22(2):215-33. PubMed PMID: 7651667.

13. Cohen SM, Lipschuetz M, Yagel S. Is a prolonged second stage of labor too long? Ultrasound in obstetrics \& gynecology: the official journal of the International Society of Ultrasound in Obstetrics and Gynecology. 2017 Oct;50(4):423-6. PubMed PMID: 28640477.

14.Maharaj D. Assessing cephalopelvic disproportion: back to the basics. Obstetrical \& gynecological survey. 2010 Jun;65(6):387-95. PubMed PMID: 20633305.

15.Sacristan-Martin O, Santed MA, Garcia-Campayo J, Duncan LG, Bardacke N, Fernandez-Alonso C, et al. A mindfulness and compassion-based program applied to pregnant women and their partners to decrease depression symptoms during pregnancy and postpartum: study protocol for a randomized controlled trial. Trials. 2019 Nov 28;20(1):654. PubMed PMID: 31779683. Pubmed Central PMCID: 6956498.

16. Hassanzadeh R, Abbas-Alizadeh F, Meedya S, Mohammad-Alizadeh-Charandabi S, Mirghafourvand M. Assessment of childbirth preparation classes: a parallel convergent mixed study. Reproductive health. 2019 Nov 7;16(1):160. PubMed PMID: 31699110. Pubmed Central PMCID: 6836369.

17. Sandall J, Tribe RM, Avery L, Mola G, Visser $\mathrm{GH}$, Homer CS, et al. Short-term and long-term effects of caesarean section on the health of women and children. Lancet. 2018 Oct 13;392(10155):1349-57. PubMed PMID: 30322585 .

18.ACOG Committee Opinion No. 761: Cesarean Delivery on Maternal Request. Obstetrics and gynecology. 2019;133(1):e73-e7. PubMed PMID: 30575678.

19.Fenwick J, Toohill J, Gamble J, Creedy DK, Buist A, Turkstra E, et al. Effects of a midwife psychoeducation intervention to reduce childbirth fear on women's birth outcomes and postpartum psychological wellbeing. BMC pregnancy and childbirth. 2015;30:15:284. PubMed PMID: 26518597. Pubmed Central PMCID: 4628230.
20. Dannenbring D, Stevens MJ, House AE. Predictors of childbirth pain and maternal satisfaction. J Behav Med. 1997; 20(2):127-142

21.Ketema DM, Leshargie CT, Kibret DG, Assemie MA, Petrucka P, Alebel A. Effects of maternal education on birth preparedness and complication readiness among Ethiopian pregnant women: a systematic review and meta-analysis. BMC Pregnancy Childbirth. 2020 Mar 6;20(1):149. 